\title{
Theoretical and experimental substantiation of the design parameters for the working body of a row cultivator
}

\author{
Evgeny Zykin ${ }^{1, *}$, and Svetlana Lazutkina ${ }^{1}$ \\ ${ }^{1}$ Ulyanovsk State Agrarian University, Ulyanovsk, Russia
}

\begin{abstract}
The authors of the article propose the design of a row cultivator, equipped with combined working bodies, which makes it possible to carry out inter-row weed control in one pass with full cultivation of the protective zones of grown crops. The soil drop distance and the distance between the flat discs located in the adjacent gangs of the row cultivator for thorough covering weed plants with a layer of soil without damage to cultivated plants have been substantiated theoretically.
\end{abstract}

\section{Introduction}

In recent years, in world practice, there has been a distinctive trend towards an increase in the use of zero tillage and direct sowing. However, it is known that with this method of cultivating farm crops, the weed infestation of the fields rises, which requires the use of herbicides and other plant protection products, the cost of which significantly increases the cost of production.

In the cultivation of crops, great importance is attached to the development and implementation of soil-protective technologies and anti-erosion machine complexes and tools. In order to reduce operating costs, to increase mobility, and lead time for technological operations, farmers buy wide-span tillage and sowing equipment, in particular, combined machines and units. Equally important for the conservation of soil fertility and ecology is the minimal use of herbicides or their complete rejection.

Ensuring energy and resource saving is a mandatory requirement that applies not only to technologies, but also to soil-cultivating and sowing equipment. New equipment should require less consumption of resources, both in the process of its production, and in the process of its operation $[1,2,3,4]$.

Row crop tending with the traditional cultivation technology provides for two or threefold mechanized inter-row cultivation, or treatment with herbicides. The width of the protective zone with each subsequent treatment increases, as a result, the area of untreated soil also increases. The use of herbicides, in addition to the positive side - the destruction of weeds by $70-80 \%$, has a negative side-a decrease in the yield of the cultivated crop to $15 \%$.

\footnotetext{
* Corresponding author: evg-zykin@yandex.ru
} 


\section{The study objects and research methods}

In order to eliminate the aforesaid disadvantages, the cultivation method [5] and means of mechanization for row crop tending have been developed $[6,7]$, which make it possible to loosen the soil and cut weeds in inter-row spacing and protective zones of rows without using environmentally unfriendly herbicides. With this method of tending crops, it is sufficient to perform one or two mechanized inter-row cultivated treatments.

Inter-row cultivation is performed by a row cultivator (Fig. 1), in each gang of which two working bodies are mounted so that their flat discs are directed towards the row of plants at a sharp angle, and the edges of the wings of the A blades are located at the lower base of the initial soil ridge formed during sowing (Fig. 2).

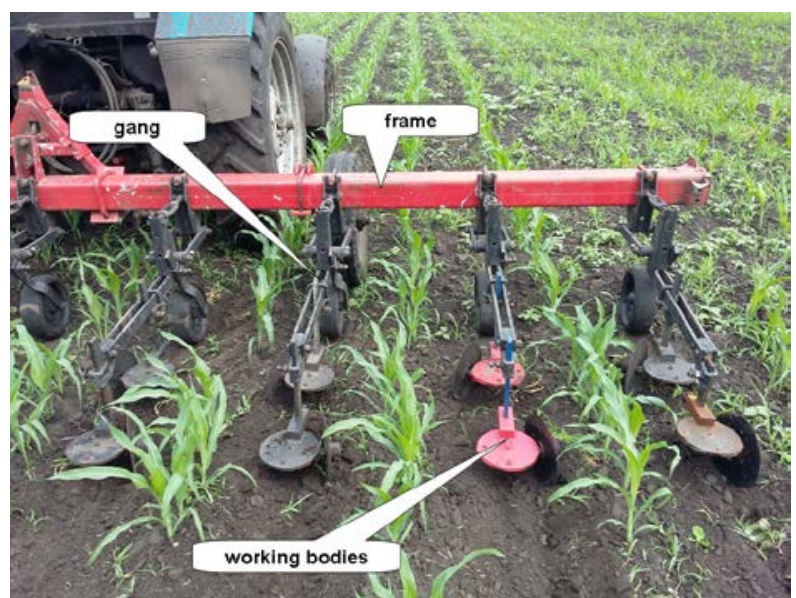

Fig. 1. Row cultivator with the proposed working bodies.

When the row cultivator is moving, the A blades 1 loosen the soil at the required depth and cut the weeds, and the flat discs 2 move the soil layer, coming from the wings of the A blades, towards the rows of plants, hill them and cover the weeds.

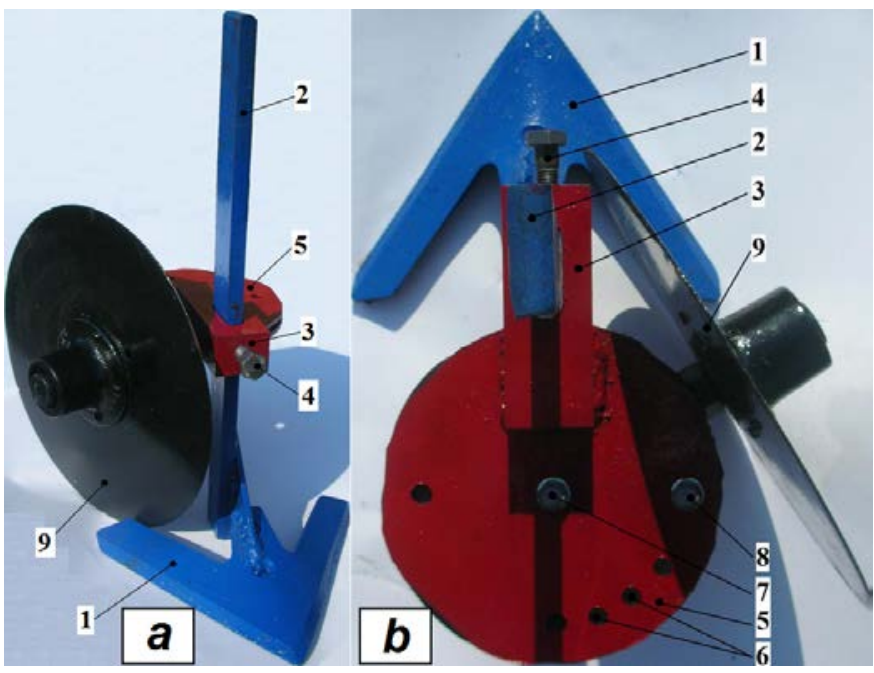

Fig. 2. The working body of a row cultivator: a - general view; b - top view; 1 - a blade; 2 - shank; 3 bracket; 4 - clamp; 5 - adjusting dial; 6 - holes; 7, 8 - bolts; 9 - flat disc 


\section{Research results}

To ensure the loosening of the soil and cutting of weed plants with A blades between the rows, as well as covering weed plants with a required layer of soil in the protective zone of the row and on the top of the soil, it is necessary to determine and substantiate the distance between the vertical axes of symmetry of flat discs and location points of working bodies on neighboring beams of a cultivator.

When a row cultivator moves with its working bodies in the seedbed, rotating flat discs throw the soil from the inter-row spacing towards the cultivated plants along a parabolic trajectory (Fig. 3).

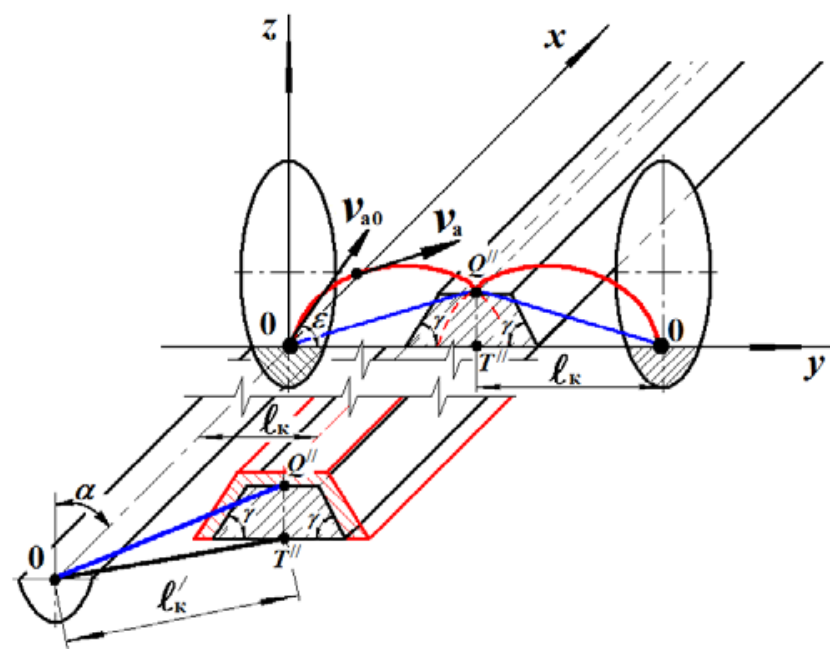

Fig. 3. Determination of the distance of throwing the soil onto the ridge.

The trajectory of the soil particles, thrown by a flat disc, is characterized by equations in coordinate form $[8]$ :

$$
\left\{\begin{array}{l}
y=v_{\mathrm{a} 0} t \cos \varepsilon, \\
z=v_{\mathrm{a} 0} t \sin \varepsilon-\frac{g t^{2}}{2} .
\end{array}\right.
$$

where $v_{\mathrm{a} 0}$ - the speed of the soil thrown by a flat disc, $\mathrm{m} / \mathrm{s} ; t$ - time of the soil movement, $\mathrm{s}$; $\varepsilon-$ the angle between the field surface and speed direction $v_{\mathrm{a} 0}$, degrees; $g$ - gravitational acceleration, $\mathrm{m} / \mathrm{s}^{2}$.

Expressing in equation (1) the parameter t, substituting it into an expression to determine the coordinate $z$ and, having made the corresponding transformations, we will get the equation, that determines the trajectory of soil particles thrown by a flat disc:

$$
z=y \operatorname{tg} \varepsilon-\frac{g y^{2}}{2 v_{\mathrm{a}}^{2} \cos ^{2} \varepsilon} .
$$

Thus, the trajectory of soil particles is a parabola, located in the plane $z 0 y$. Knowing that the speed of the thrown soil changes from $v_{\mathrm{a} 0}=0$ to the absolute speed $v_{\mathrm{a}}$ over time $t$, then the soil thrown acquires acceleration $\bar{a}$, in the direction that coincides with $\bar{v}_{\mathrm{a}}$. 
It is required to bear in mind that the maximum distance of the soil thrown should correspond to the distance $\mathrm{O}_{4} Q^{/ /}$. In this case weed plants in the protective zone, as well as on the top of the ridge and on its lateral sides will be covered with a layer of the soil of the required thickness. If the maximum distance of moving the soil is less than the distance $\mathrm{O}_{4} Q^{\prime /}$, then weed plants on the soil ridge will be left uncovered. If the maximum distance of throwing the soil is greater than the distance $\mathrm{O}_{4} Q^{\prime /}$, then the soil particles will fly over the initial soil ridge, and also will damage the crops.

From figure 3 it follows that the length $O_{4} Q^{/ /}$is the projection on the plane $y 0_{4} z$ of a parabolic soil flying path. Then

$$
z=y \operatorname{tg} \gamma,
$$

where $\gamma$ - the angle of natural repose of the original soil ridge formed during sowing, deg.

The soil thrown by a flat disc is to end its movement at the point $Q^{\prime \prime}$. In this case ordinates $z$, determined with equations (2) and (3) will be equal. Consequently,

$$
y \operatorname{tg} \varepsilon-\frac{g y^{2}}{2 v_{\mathrm{a}}^{2} \cos ^{2} \varepsilon}=y \operatorname{tg} \gamma .
$$

Expressing the abscissa from equation (4) and performing the appropriate transformations, we determine the distance $\mathrm{O}_{4} Q^{\prime /}$ from the vertical axis of symmetry of the flat disc (the place of soil separation from a flat disc) to the final path of the soil flying path:

$$
y=O_{4} Q^{\prime \prime}=\frac{v_{\mathrm{a}}^{2}\left(\sin 2 \varepsilon-2 \cos ^{2} \varepsilon \operatorname{tg} \gamma\right)}{g} .
$$

From fig. 3 it follows that the distance

$$
\left(O_{4} Q^{\prime /}\right)^{2}=\left(O_{4} T^{/ /}\right)^{2}+\left(Q^{/ /} T^{/ /}\right)^{2},
$$

or, taking account of the expression (5):

$$
\ell_{\mathrm{K}}^{\prime}=O_{4} T^{\prime \prime}=\sqrt{\left[\frac{v_{\mathrm{a}}^{2}\left(\sin 2 \varepsilon-2 \cos ^{2} \varepsilon \operatorname{tg} \gamma\right.}{g}\right]^{2}-H_{\mathrm{r}}^{2}},
$$

where $H_{\Gamma}=Q^{/ /} T^{/ /}$- the height of the original soil ridge formed during sowing, $\mathrm{m}$.

The distance, $m$, between the vertical axes of symmetry of flat discs located on the adjacent beams of the cultivator, in the mechanized treatment of row crops

$$
L_{\mathrm{K}}=2 \ell_{\mathrm{K}},
$$

where $\ell_{\mathrm{\kappa}}-$ the distance between the vertical axis of symmetry of a flat disc and the longitudinal axis of symmetry of the ridge of the soil formed during sowing, $\mathrm{m}$.

Since the flat disc during inter-row cultivation is set to the direction of movement at the angle of attack $\alpha$, then in the direction perpendicular to the direction of movement of the row cultivator, the soil thrown will move to a distance

$$
\ell_{\mathrm{K}}=\ell_{\mathrm{K}}^{\prime} \cos \alpha=\cos \alpha \sqrt{\left[\frac{v_{\mathrm{a}}^{2}\left(\sin 2 \varepsilon-2 \cos ^{2} \varepsilon \operatorname{tg} \gamma\right.}{g}\right]^{2}-H_{\mathrm{r}}^{2}} .
$$


Taking into account, that the absolute speed of the soil moved to the side

$$
v_{\mathrm{a}}=\frac{2 v_{\mathrm{c}} \cos \alpha \operatorname{tg} \alpha}{2 \cos \beta},
$$

then, substituting (9) in (8), as well as taking account of expression (10), we will determine the distance between flat discs, located on the neighboring beams of the cultivator in case of mechanized cultivation of row crop seedlings:

$$
L_{\mathrm{\kappa}}=2 \cos \alpha \sqrt{\left[\frac{2 v_{\mathrm{c}} \cos \alpha \operatorname{tg} \alpha\left(\sin 2 \varepsilon-2 \cos ^{2} \varepsilon \operatorname{tg} \gamma\right.}{2 g \cos \beta}\right]^{2}-H_{\mathrm{r}}^{2}},
$$

where $\beta$-the friction angle, $\beta=\operatorname{arctg} f ; f-$ the coefficient of soil friction on a steel flat disc.

\section{Conclusion}

Thus, the distance between the flat discs (vertical axes of symmetry) of the working bodies located in the adjacent gangs of the row cultivator depends on the speed of its movement, the angle of attack of the flat discs, as well as the physical and mechanical properties of the soil.

\section{References}

1. The law of fruit change: the economic and energy efficiency of crop rotation / V.P. Zaikin, A.E. Shamin, A.Yu. Lisina, E.E. Borisova // Bulletin of NSIEE. - 2016. - № 3 (58). 2016. - pp. 72-80.

2. Osokin, V.L. Methodological issues of an objective assessment of energy saving potential / V.L. Osokin, B.V. Papkov, V.A. Gorokhov // Bulletin of NSIEE. - 2016. - № 4 (59). 2016. - pp. 98-106.

3. Soybean cultivation in the Ulyanovsk region: practical recommendations / A.V. Dozorov, A.Yu. Naumov, Yu.V. Yermoshkin, M.N. Garanin, A.V. Voronin, Yu.M. Rakhimov. - Ulyanovsk: USSA named after P.A.Stolypin, 2014. - p.59.

4. Emelyanov, P.A. Theoretical and experimental studies of the covering disc of an onion planter: monograph / P.A. Yemelyanov, A.V. Sibirev, A.G. Aksenov. - Penza: Penza State Agricultural Academy, 2015. - p. 174.

5. Patent 2443094 Russian Federation, IPC A01B79 / 02, A01G1 / 00. The method of cultivation of row crops / V.I. Kurdyumov, E.S. Zykin; applicant and patent holder of FGOU VPO "Ulyanovsk State Agricultural Academy". - № 2010141211/13; declare 10/7/2010; publ. 27.02.2012, Bull. No. 6.

6. Kurdyumov, V.I. New cultivator tool / V.I. Kurdyumov, E.S. Zykin, I.A. Sharonov // Rural mechanizer. - 2012. - № 11 (45). - p. 12.

7. Patent 2507730 Russian Federation, IPC A01B39 / 18. Row cultivator / V.I. Kurdyumov, E.S. Zykin; applicant and patent holder FSBEI HPE "Ulyanovsk State Agricultural Academy named after P.A. Stolypin”. - № 2012137736/13; declare September 4, 2012; publ. 02.27.2014, Bull. No. 6.

8. Bat, M.I. Theoretical mechanics in examples and mathematical problems. Volume $2 /$ M.I. Bat, G.Yu. Janelidze, A.S. Kelzon - SPb .: Publishing house "Lan”, 2010. - p. 640. 